\title{
PHARMACOLOGY OF THE VESTIBULAR HAIR CELL-AFFERENT FIBER SYNAPSE IN THE FROG ${ }^{1}$
}

\author{
J. -M. ANNONI, S. L. COCHRAN, ${ }^{2}$ and W. PRECHT \\ Brain Research Institute, University of Zürich, Zürich, Switzerland
}

Received November 14, 1983; Revised March 14, 1984; Accepted March 21, 1984

\begin{abstract}
The isolated, intact, membranous labyrinth of the frog (Rana temporaria) has been investigated electrophysiologically in vitro to determine the nature of the transmitter substance at the synapse between the vestibular hair cells and afferent fibers. Spontaneous synaptic activity can be monitored with intra-axonal recordings from the afferents. Increased $\mathrm{K}^{+}$in the bath results in an increase in frequency of presynaptic release, as indicated by an increased frequency of spontaneous synaptic potentials. Adding $\mathrm{Mg}^{21}$ and lowering $\mathrm{Ca}^{21}$ results in a decrease in synaptic potential frequency (often to zero) with no change in their mean amplitude, indicating pre-synaptic blockade.

Extracellular recordings from individual vestibular afferents indicate that bath-applied glutamate and related acidic amino acids consistently increase the firing rates of these afferents in a dose-dependent manner with no evidence of desensitization. In the presence of presynaplic blockade (high $\mathrm{Mg}^{2+} / \mathrm{low} \mathrm{Ca}^{2+}$ ), bath application of glutamate and its agonists results in a reversible depolarization of vestibular afferents, suggesting a postsynaptic action of these substances. 2-Amino-5-phosphonovaleric acid, kynurenic acid, and other acidic amino acid antagonists reversibly decrease the amplitudes of spontaneously occurring synaptic potentials without affecting their frequency, indicating subsynaptic blockade. These antagonists also block the postsynaptic depolarizations due to glutamate and its agonists. GABA and its agonists and antagonists have no consistent effect upon afferent activity.

These findings suggest that glutamate, aspartate, or a related compound is the transmitter at this synapse. However, the antagonists used, or the receptors themselves, are not selective enough to discriminate adequately between the agonists. Therefore, which of these glutamate agonists are actually involved in synaptic transmission remains to be determined.
\end{abstract}

Afferent fibers that project to the brain from the vestibular labyrinth of the frog are somewhat unique as neurons in that they are contacted by only one type of synapse, that from the type II hair cell (Hillman, 1976). Type I hair cells, found in addition in higher vertebrates, are lacking in the frog. Therefore, the vestibular labyrinth of the frog is an ideal system, in terms of its relative simplicity, to investigate the physiology and pharmacology of synaptic transmission, particularly as the membranous labyrinth (as well as other regions of the amphibian nervous system) can be isolated and maintained in a viable state for many days.

Previous studies of synaptic transmission between hair cells and different fibers from the frog semicircular canals have revealed the presence of small, tetrodotoxin (TTX)-insensitive, depolarizing potentials in the afferents that summate and give rise to 'I"IX-sensitive action potentials (Rossi et al., 1977). The

\footnotetext{
${ }^{1}$ This research was supported by the Swiss National Science Foundation (Grants 3.505.79 and 3.616.80) and by the Dr. Eric Slack-Gyr Foundation. We thank Ruth Emch, Rico Gysin, Elisabeth Hitz, Johann A. Künzli, Gaby Mack, and Eva Schneider for their technical assistance in the preparation of the manuscript.

${ }^{2}$ To whom correspondence should be addressed, at Brain Research Institute, University of Zürich, August-Forel-Str. 1, CH-8029 Zürich, Switzerland.
}

frequency of these depolarizing potentials is modified by rotation of the semicircular canal, and their presence is reduced or abolished in high concentrations of $\mathrm{Mg}^{2+}$ and low concentrations of $\mathrm{Ca}^{2+}$, suggesting that these potentials are EPSPs arising from the hair cells and that this synaptic transmission is chemical in nature.

Very few studies have investigated synaptic pharmacology in the vestibular labyrinth (possibly due to its inaccessibility), but those that have suggest that the hair cell transmitter may be a catecholamine (Osborne and Thornhill, 1972) or GABA (Flock and Lam, 1974; Felix and Ehrenberger, 1982; Meza et al., 1982). Investigations of the nature of the synaptic transmitter at other hair cell-peripheral nerve junctions, such as in the cochlea (Klinke and Oertel, 1977; Bobbin 1979; Comis and Leng, 1979) or lateral line (Steinbach and Bennett, 1971; Teeter and Bennett, 1981), implicate glutamate, or something similar, as the afferent transmitter.

To investigate the pharmacology of the vestibular hair cellafferent fiber synapse electrophysiologically, we have bathapplied a number of putative neurotransmitter substances and their antagonists to the isolated peripheral labyrinth of the frog to assess their similarities with the endogenous transmitter substance. Since the vestibular afferent is innervated by only one type of nerve terminal - the hair cell-this synapse may prove a model (much as is the neuromuscular junction) for 
investigations of synaptic physiology and transmitter actions. An understanding of synaptic physiology in this system could then lead to a general understanding of synaptic excitation of multiply innervated neurons in the CNS. Therefore, we hoped that an investigation of this relatively simple system would relieve some of the ambiguity of interpretation arising from electrophysiological investigations of exogenous and endogenous chemical action in more complex regions of the nervous system. Preliminary results of this study have been previously published in abstract form (Annoni et al., 1983a, b).

\section{Materials and Methods}

Isolation of the labyrinth. Experiments were performed upon more than 65 frogs (Rana temporaria). A frog was placed into a beaker of $0.2 \%$ MS222 (ethyl- $m$-aminobenzoic acid diethyl ester) until all signs of reflexive activity ceased and then placed into ice for a period of approximately $30 \mathrm{~min}$. Following cooling, the frog was perfused through the heart with $10 \mathrm{ml}$ of iced, oxygenated, normal saline (composition: $\mathrm{NaCl}, 75 \mathrm{~mm}$; $\mathrm{NaHCO}_{3}, 25 \mathrm{~mm}$; KCl, $2 \mathrm{~mm} ; \mathrm{CaCl}_{2}, 2 \mathrm{mM}$; glucose, 11 $\mathrm{mM}$; bubbled with $95 \% \mathrm{O}_{2} / 5 \% \mathrm{CO}_{2}$ so that $\mathrm{pH}=7.4$ at $21^{\circ} \mathrm{C}$ ). This perfusion was followed by decapitation and removal of the brain and then by carefully (under microscopic control) chipping the bone away from the membranous labyrinth it enclosed. The clear membrane that envelops the membranous labyrinth was dissected away from critical zones near the ampullae of the semicircular canals, because the presence of this membrane hindered electrode and drug penetration. The intact, membranous labyrinth was then fixed by cyanoacrylate glue to a porous plastic film (Band-aid, Johnson \& Johnson Products; or Telfa, Colgate-Palmolive Co.) which was, in turn, fixed to a less flexible plastic base. The surgical procedure generally lasted 15 to $30 \mathrm{~min}$, and subsequently the preparation appeared viable-i.e., spontaneous activity could readily be recorded from individual fibers in each ampullary nerve branch (Fig. 1). Those labyrinths that were mechanically damaged took a long time to dissect, or were dissected at room temperature were less viable as judged by the above criterion. If the labyrinth was maintained overnight at less than $10^{\circ} \mathrm{C}$, it would remain viable for several days.

Electrophysiology. This preparation was then submerged in a temperature-controlled $\left(14\right.$ to $\left.16^{\circ} \mathrm{C}\right)$ bath, having an adjustable volume (normally approximately $0.5 \mathrm{ml}$ ). Standard microelectrode recording techniques were used. Electrodes were filled with $1 \mathrm{M}$ potassium citrate or $3 \mathrm{M}$ potassium methyl sulfate and had a resistance of between 50 and 150 megohms after beveling (Brown and Flaming, 1974). Electrode tips were too small to be visualized with light microscopy (even after beveling), indicating that their diameters were less than $0.5 \mu \mathrm{m}$. The electrode was attached to a bridge amplifier (allowing current injection), the output of which was connected to an oscilloscope, a chart recorder, a Nicolet 1170 signal averager, and an analogue tape recorder for onand off-line analyses. Vertical movements of the microelectrode were controlled by a motorized step-manipulator (Sonnhof et al., 1982). Occasionally, bipolar stimulating electrodes (tip approximately $200 \mu \mathrm{m}$ diameter) were placed upon the branches or stump of the vestibular nerve, and constant current pulses ( 0.1 to $3 \mathrm{~mA} ; 100 \mu \mathrm{sec})$ were applied to elicit action potentials in impaled axons. Recording electrodes were manipulated under visual control (Wild M-5A dissecting microscope; magnification $\times 120$ to 1000 ) so that electrode tips were inserted into the fine nerve branches less than $1 \mathrm{~mm}$ and usually within $250 \mu \mathrm{m}$ from their ampullary exits (Fig. 1).

Pharmacology. All solutions were freshly prepared or stored frozen prior to use. It was necessary to apply test substances to the bath, because insertion of an iontophoretic electrode through the canal resulted in mechanical damage of the crista.

The labyrinth was continuously superfused $(\sim 2 \mathrm{ml} / \mathrm{min})$. Solutions could be changed within $5 \mathrm{sec}$ with a method similar to that previously described (Quastel et al., 1971; Hackett, 1976). Drug effects, when present, could be readily observed within $1 \mathrm{~min}$, if not sooner. The variability between different labyrinths in the extent of diffusion of substances prevented any meaningful assessment of the relative time course of effect of the applied substances, except as stated under "Results." Osmolarity or pH changes, due to the addition of substances, did not have a significant effect upon afferent activity, in that substances of similar concentrations or charges could have opposing or no effects.

Chemicals were for the most part obtained from Sigma. However, $N$-methyl- $D$-aspartic acid, quisqualic acid, muscimol, and most of the acidic amino acid antagonists were purchased from Cambridge Research Biochemicals, England.

\section{Results}

\section{Identification of vestibular afferents}

Electrodes inserted into nerve branches less than $1 \mathrm{~mm}$ from their ampullary exits (Fig. 1) can record spontaneous synaptic and spike potential activity (Rossi et al., 1977). Four types of cells can be detected. Two types exhibit spontaneous action potential activity in extracellular recordings and are distinguishable from each other by their firing characteristics. One type has a regular firing frequency, while the other fires more sporadically-i.e., irregularly bursting and pausing. Both types, upon impalement, have spontaneous miniature depolarizing potentials that give rise to action potentials. These neurons are also activated antidromically from electrical stimulation of the vestibular nerve stump. We conclude that these are afferents. Another cell type has no resting firing rate but can be activated from electrical stimulation of the vestibular nerve stump, and spontaneous potentials are not evident in these cells. They may represent efferent fibers or afferents, mechanically separated from their afferent hair cells. A fourth type of cell, whose magnitude of resting membrane potential is very high (over 80 $\mathrm{mV}$ ), is not activated by electrical stimulation of the vestibular nerve stump or ganglion or by the addition of $10 \mathrm{mM} \mathrm{K}^{+}$to the bath (although this addition resulted in depolarization), suggesting that these cells are electrically inexcitable. These cells then may represent supporting elements.

This study will only report results obtained from the afferents. These axons are extremely difficult to impale without damage because of their small size ( 1 to $10 \mu \mathrm{m}$; see Hillman, 1976). Successful impalements are frequently of rather short duration for similar reasons. Even extracellularly it is difficult to maintain axonal recordings for long periods of time. Often when the magnitude of the resting membrane potential is very low (less than $20 \mathrm{mV}$ ), the spontaneous synaptic potentials can be readily detected. This ability may be due to the electrode being wedged between layers of myelin, and, thus, it is able to record activity from the "true" axon, even though in the surrounding myelin the resting membrane potential is low. Therefore, intracellular recordings are arbitrarily defined as any impalement whose magnitude of resting membrane potential exceeds $40 \mathrm{mV}$. We have not found any significant pharmacological differences between the regularly and irregularly firing

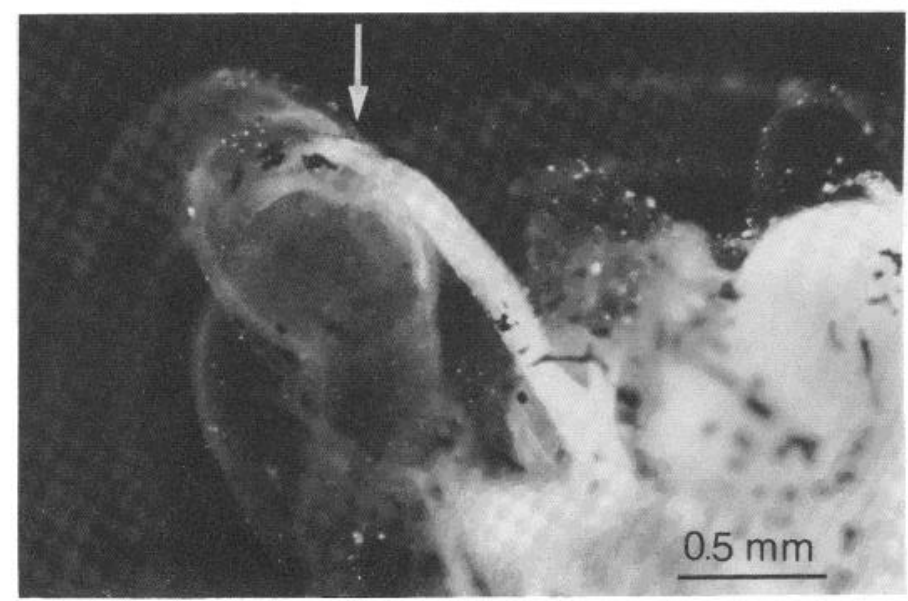

Figure 1. Photomicrograph of a portion of the isolated labyrinth showing the ampulla of the posterior semicircular canal and the afferent nerve emerging from it. The arrow depicts the approximate position of the recording microelectrode. Magnification $\times 30$. 
afferents and, therefore, have grouped the two in the subsequent "Results." Neither did the pharmacological responses appear to differ with respect to the particular canal afferents from which we recorded (i.e., posterior versus anterior or horizontal).

\section{Spontaneous synaptic activity}

The firing characteristics of the afferents are dependent upon the underlying spontaneous synaptic activity. When the frequency of occurrence of the synaptic potentials is high, then different fibers tend to fire regularly at a high frequency. In other fibers, synaptic potentials are rare, and sudden clusters, which give rise to a few action potentials, appear and result in a fiber's irregular firing characteristics. Changes in the ionic composition of the bath can alter the spontaneous synaptic potential activity. The addition of $3 \mathrm{mM} \mathrm{K}^{+}$to the bath, for instance, results in an increase in the frequency of these poten- tials (Fig. 2, $A$ and $B$ ) with little change in their amplitude (Fig. $2 B$ ), indicating an increase in transmitter release from the hair cells. The addition of $10 \mathrm{mM} \mathrm{Mg}^{2+}$ and reduction of $\mathrm{Ca}^{2+}$ to $1 \mathrm{mM}$ reduces and abolishes the number of these spontaneous potentials (Fig. $3, A$ and $B$ ) but does not change their amplitude (Fig. $3 B$ ), indicating presynaptic blockade. During such blockade, the afferent no longer fires action potentials (although the axon can be stimulated to do so; Fig. 4), indicating that the resting activity of the vestibular afferent is heavily dependent upon the state of hair cell activity. Low $\mathrm{Ca}^{2+}$ $(0.1 \mathrm{mM})$ alone resulted in a large increase in excitability in the afferent as well as an increase in the frequency of spontancous synaptic potentials (Fig. 5) similar to the effects seen by Russell (1971) in Xenopus lateral line. This effect was not studied in detail, but $1 \mathrm{mM} \mathrm{Ca}{ }^{2+} / 10 \mathrm{mM} \mathrm{Mg}^{2+}$ was empirically found to prevent this increase in excitability as well as to block totally the occurrence of spontaneous synaptic potentials.

A
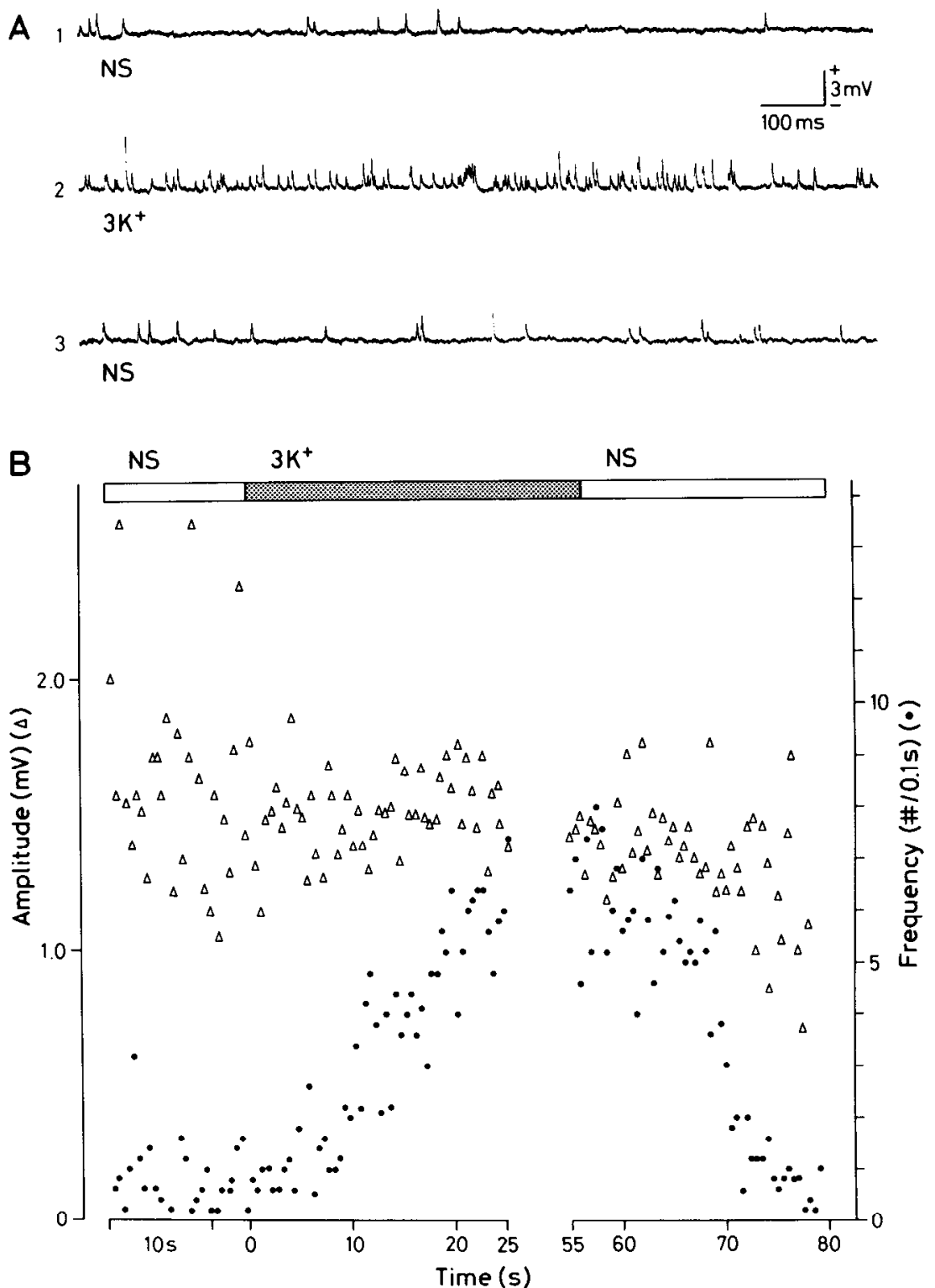

Figure 2. Effect of increased $\mathrm{K}^{+}$on spontaneous synaptic potentials. $A$, Intracellular recordings from an efferent fiber in normal saline $(A 1, N S)$, after the addition of $3 \mathrm{mM}$ $\mathrm{K}^{+} \mathrm{lo}$ the bath $\left(A 2,3 K^{+}\right)$, and following return and washout from the increased $\mathrm{K}^{+}(A 3$, $N S)$. B, Plot of amplitude $(\triangle)$ and frequency $(\bullet)$ of spontaneous synaptic potentials from the cell shown in $A$ before $(N S)$, during ( $3 K$, shaded), and after removal of $\mathrm{K}^{+}$ from the bath (second NS). 
A
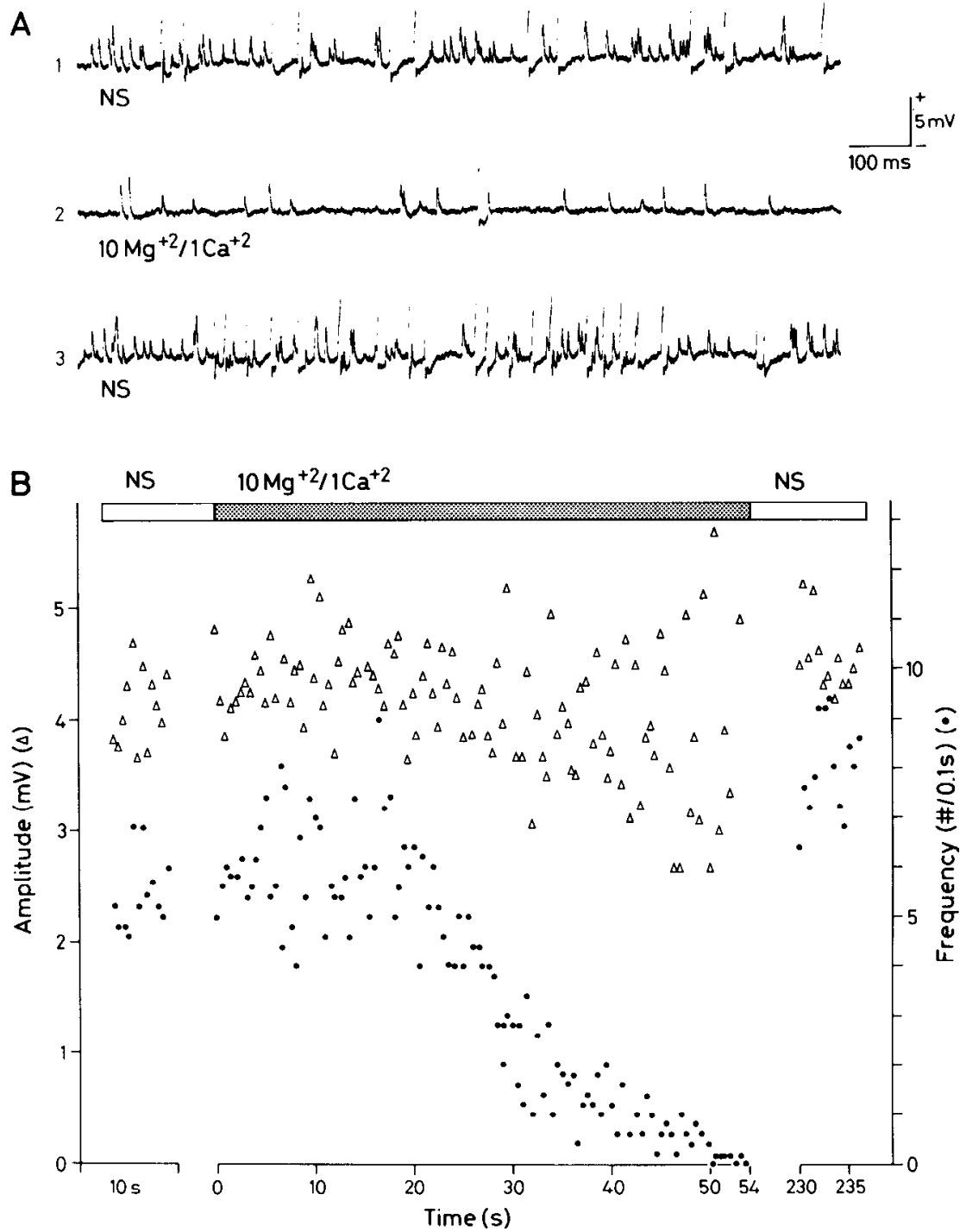

Figure 3. Effect of the addition of $\mathrm{Mg}^{2+}$ and reduction of $\mathrm{Ca}^{2+}$ in the bath on the spontaneous synaptic potentials. $A$, Intracellular recordings from a vestibular afferent as in Figure 2. A1, Control response; $A 2$, in the presence of $10 \mathrm{mM} \mathrm{Mg}^{2+}$ and $1 \mathrm{mM} \mathrm{Ca}^{2+}$; $A 3$, recovery in normal saline $(N S)$. Action potentials are cut off. $B$, Plot of amplitude $(\triangle)$ and frequency $(\bullet)$ of spontaneous synaptic potentials from the cell shown in $A$ and the effect of $10 \mathrm{mM} \mathrm{Mg}^{2+} / 1 \mathrm{mM} \mathrm{Ca}{ }^{2+}$.

A

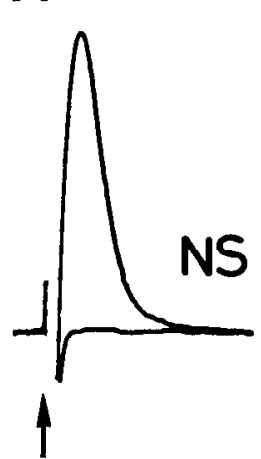

B
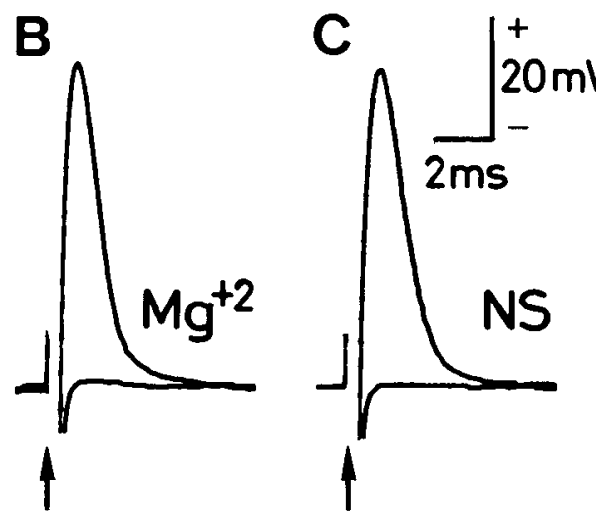

Figure 4. Action potentials evoked in a single afferent by electrical stimulation of the eighth nerve (arrows). A, Intracellularly recorded action potential in normal saline (NS); $B$, the same fiber in $10 \mathrm{mM}$ $\mathrm{Mg}^{2+} / 1 \mathrm{mM} \mathrm{Ca}{ }^{2+}\left(\mathrm{Mg}^{+2}\right)$ when synaptic transmission was blocked; $C$, after returning to normal saline.

\section{Excitatory substances}

Table I lists various compounds and their effects on the spontaneous activity of individual afferents, extracellularly recorded. The most consistently exciting class of substances is glutamate and its related acidic amino acids. These substances cause a marked increase in firing rates (Fig. 6) and often result, depending upon concentration and duration of application, in depolarization inactivation of the afferents (Figs. 6, $A, B, E$ and $F$, and $7 A$, inset) as evidenced by a high rate of firing of the cell, a decrease in spike amplitude, and an increase in spike duration, both intracellularly and extracellularly. Effects are maintained throughout the period of application, indicating no desensitization, and are completely reversible. A given acidic amino acid could be applied repeatedly as well, without significantly changing the afferent's response, again suggesting that any desensitizing process is minimal if not absent. The dose dependence of these effects is shown for glutamate and aspartate in Figure 7A. The threshold for activation is between 0.1 and $0.2 \mathrm{mM}$. Glutamate and aspartate are not significantly 


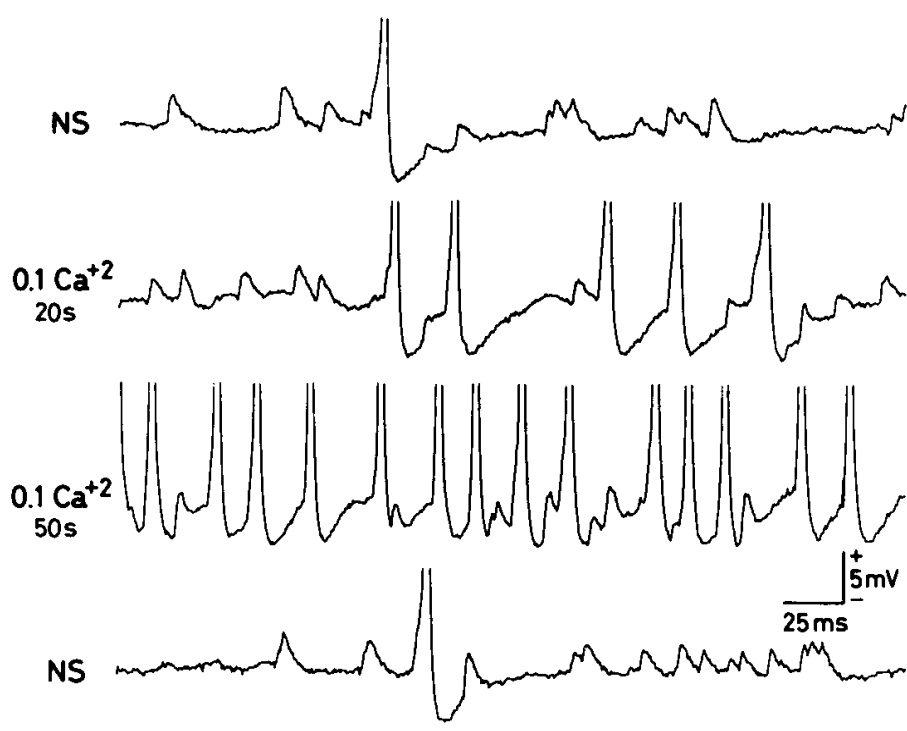

Figure 5. Effect of $0.1 \mathrm{mM} \mathrm{Ca}{ }^{2+}$ on afferent fiber activity. Spontaneous synaptic potential and action potential frequency increase. Returning to normal saline (NS) reverses this effect.

different in their ability to activate the afferents. Overall, glutamate, aspartate, homocysteic acid, and their isomers are relatively equipotent in their ability to excite the afferents, whereas quinolinic acid is clearly less potent. $N$-Methyl-aspartic acid, however, is relatively more potent, and kainic and quisqualic acids are considerably more potent in their ability to excite (Fig. $7 B$ ).

\section{Site of action}

Glutamate-induced depolarizations of the afferent in normal saline (Fig. $8 A$ ) persist when the synapses are presynaptically blocked (Fig. $8 B$ ) (as evidenced by the reduction in frequency but not amplitude of spontaneous synaptic potentials in $10 \mathrm{mM}$ $\mathrm{Mg}^{2+} / 1 \mathrm{mM} \mathrm{Ca}^{2+}$ ), indicating that glutamate acts postsynaptically. Over a wide range of concentrations, both glutamate and aspartate depolarizations are relatively independent of whether the synapse is presynaptically blocked (Fig. 9). Attempts to record conductance changes induced by glutamate or aspartate resulted in inconsistent findings, possibly due to the high resistance of the electrodes, the small diameter of the impaled axons, and the rather distant location of the recording site from the synapses within the crista.

\section{Pharmacological blockade of synaptic-and acidic amino acid-induced excitation}

Synaptic transmission. A wide variety of antagonists of the actions of acidic amino acids (see Watkins and Evans, 1981) blocks synaptic transmission. Examples of the actions of two of these substances, 2-amino-5-phosphonovaleric acid (APV) and kynurenic acid (KENYA) (Perkins and Stone, 1982) are depicted in Figures 10 and 11, respectively. In both cases the synapses were only partially blocked because of the long time needed to produce full recovery. Long exposures resulted in nearly complete blockade (Fig. 12), which was in most instances partially reversible. The reversibility of the effects of the antagonists was clear from extracellular recordings, which were stable for long enough periods of time to obtain full recovery. Both APV and KENYA decreased the amplitude of the spontaneous synaptic potentials (APV: Fig. 10, $A 2, B$, and $C 2$; KENYA: Fig. $11 A 2$ and $B$ ) without significantly affecting their frequency of occurrence (APV: Fig. 10B; KENYA: Fig. 11B). The relative potency of these blocking agents is depicted in Figure 12. APV, KENYA, 2-amino-4-phosphonobutyric acid
(APB), $\gamma$-D-glutamylglycine ( $\gamma$-DGG), cis-2,3-piperidine dicarboxylic acid (PDA), and 2-amino-3-phosphonopropionic acid were significantly more potent in blocking the synapses than were glutamic acid diethyl ester (GDEE) or $\alpha$-aminoadipic acid $(\alpha-\mathrm{AA})$.

Amino acid-induced excitation. These agents that block spontaneous synaptic transmission also reversibly block the postsynaptic amino acid-induced depolarizations. The actions of APV and KENYA in antagonizing aspartate, glutamate, and (for KENYA) quisqualic acid depolarizations are shown in Figures 13 and 14. The excitatory effect of kainic acid was also blocked by KENYA. Figure 15 summarizes the actions of these two antagonists upon the amino acid-induced excitations. Glutamate was generally more resistant to blockade than were aspartate, quisqualic acid, and kainic acid. Because of the technical difficulties encountered impaling these axons, we were not able to assess adequately the relative potencies of each of these antagonists with respect to all of the agonists, except as indicated above.

\section{GABA and other substances}

GABA and its potent agonist muscimol were found in some instances to excite the vestibular afferents (Table I). However, when the synapses were blocked presynaptically with high $\mathrm{Mg}^{2+}$ and low $\mathrm{Ca}^{2+}$, even though glutamate and aspartate could still depolarize postsynaptically, neither GABA (4 cells) nor muscimol (10 cells; Fig. 16) had a significant effect upon the resting membrane potential of the afferent. In addition, antagonists of GABA (bicuculline and picrotoxin) had no consistent effect upon the spontaneous synaptic potentials. To rule out the possibility of diffusion barriers for these high molecular weight compounds, in one case $0.1 \mathrm{~mm}$ picrotoxin was continuously superfused for $7 \mathrm{hr}$. Even in this instance, spontaneous synaptic activity could easily be detected in more than 10 afferents.

Epinephrine and carbachol were also found in some cases to excite the afferents (Table I). Although not investigated in detail, this excitation appeared to result from an increase in synaptic potential frequency rather than from a direct depolarization of the afferent, indicating a presynaptic effect. In addition, curare does not block spontaneous synaptic activity (Rossi et al., 1980). (More recent studies (Bernard et al., 1984) indicate that the effects of cholinergic agonists are entirely presynaptic.)

\section{Discussion}

The spontaneous synaptic potentials recorded from vestibular afferents are similar to the spontaneous miniature endplate potentials recorded from the neuromuscular junction (Fatt and Katz, 1952; Del Castillo and Katz, 1954). In both cases the frequency is increased by increasing the extracellular $\mathrm{K}^{+}$concentration and is decreased by decreasing the extracellular $\mathrm{Ca}^{2+}$ concentration and adding $\mathrm{Mg}^{2+}$. These similarities imply that the mechanisms of depolarization-secretion coupling are similar between the hair cell and motoneuron terminal. A similar conclusion was obtained by Furukawa et al. (1972), who recorded from auditory afferents in the goldfish. The level of polarization of each terminal type then determines, through $\mathrm{Ca}^{2+}$ entry, the frequency of transmitter release giving rise to these spontaneous generator potentials in the vestibular afferent or that of the miniature endplate potentials in muscle cells. Hair cells, which become depolarized from stereocilial deflection (Hudspeth and Jacobs, 1979), would then be expected to increase the frequency of spontaneous transmitter release and give rise to the postsynaptic depolarizations observed following cupular displacement (Rossi et al., 1977).

However, the pharmacology of the hair cell-afferent fiber synapse is not cholinergic, as at the neuromuscular junction, 
TABLE I

Extracellular responses of vestibular afferents to bath application of various substances

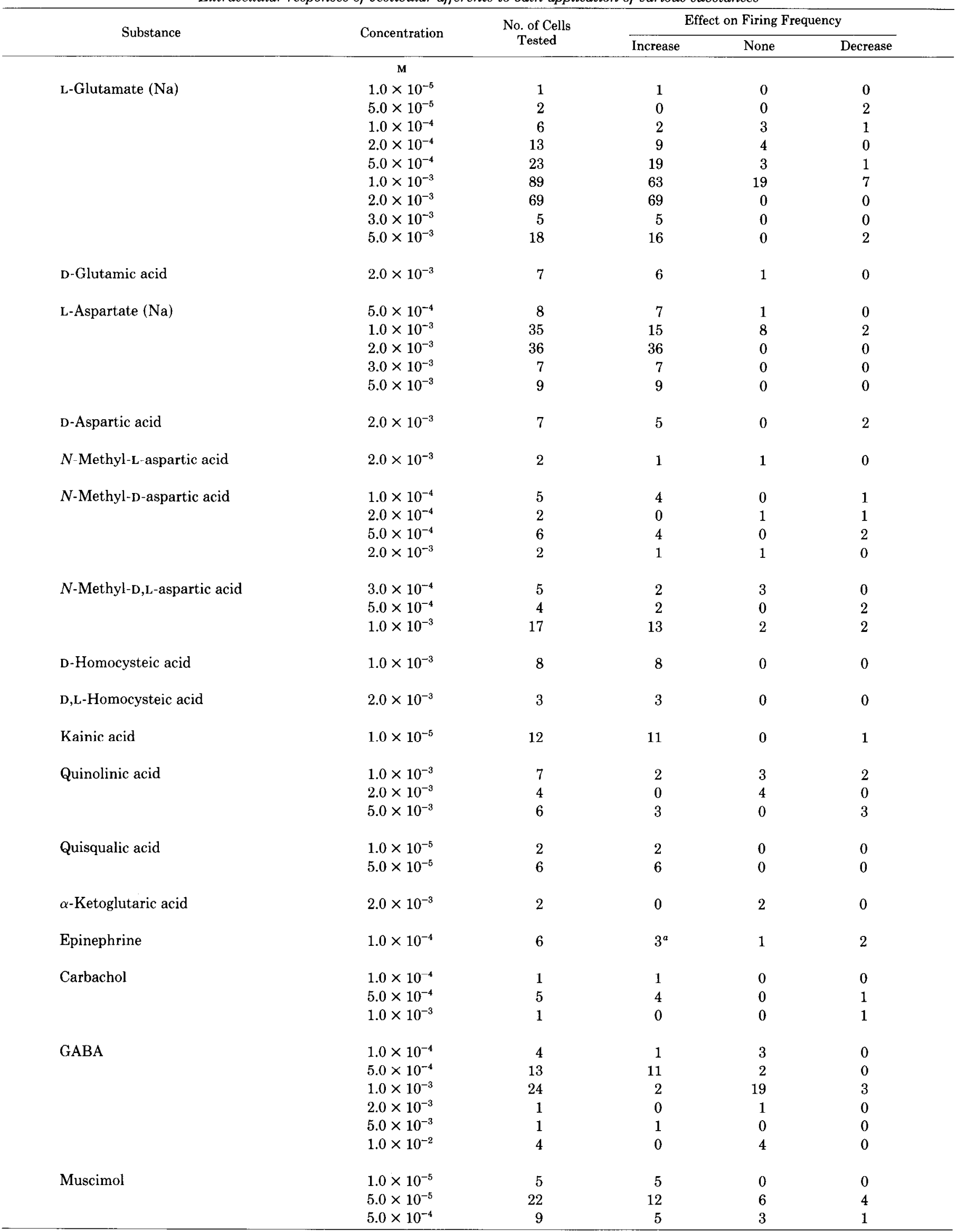

\footnotetext{
${ }^{a}$ This increase was less than $10 \%$ above the firing rate at rest.
} 

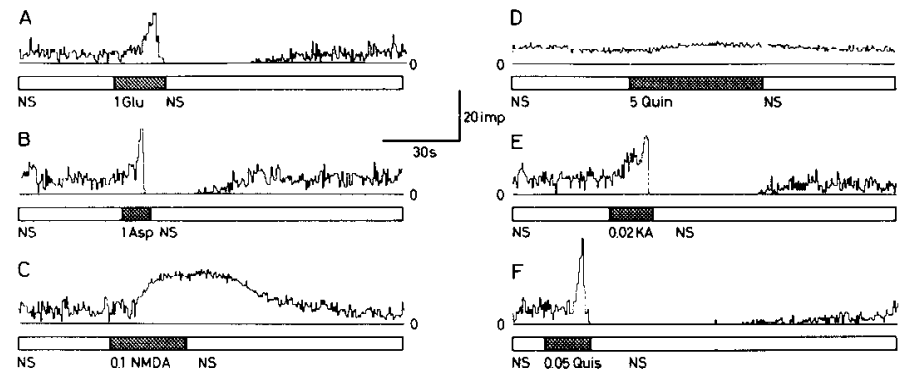

Figure 6. Effect of bath application of acidic amino acids on the spontaneous firing rates of individual afferent fibers recorded extracellularly. Each interval in rate record represents the number of spikes occurring in 1 sec. $A$ to $F$, Different cells excited by L-glutamate (Glu) in $A$; L-aspartate $(A s p)$ in $B ; N$-methyl-D-aspartic acid (NMDA) in $C$; quinolinic acid (Quin) in $D$; kainic acid (KA) in $E$; and quisqualic acid (Quis) in $F$. The numbers before each substance indicate millimolar concentrations. In $A, B, E$, and $F$, the cells became inactivated by depolarization. Shaded regions represent the time the afferent fiber was exposed to a given amino acid. NS normal saline.

(A)
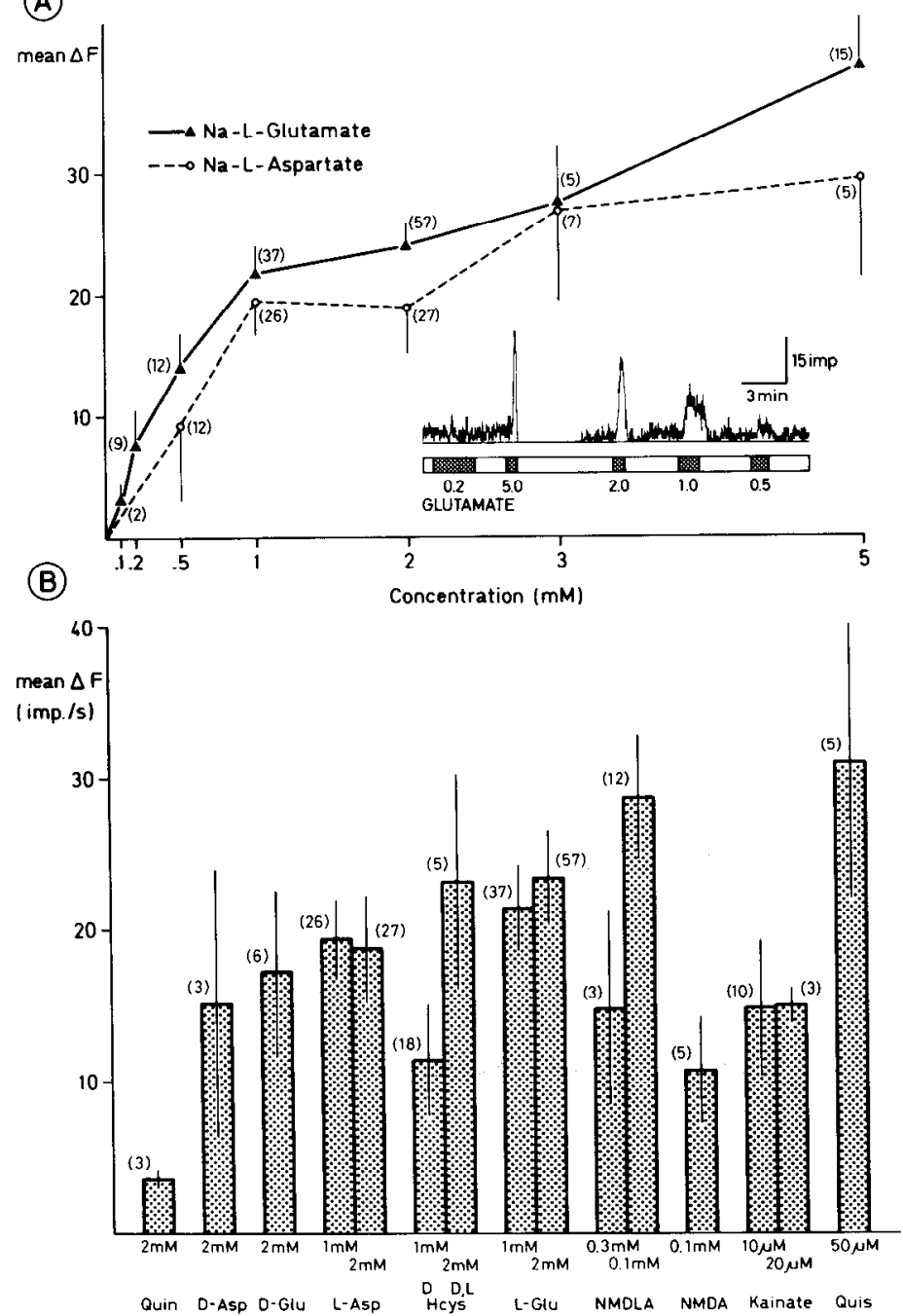

Figure 7. Dose-response characteristics of acidic amino acids on afferent excitation, recorded extracellularly. $A$, Dose-response curves to glutamate $(\boldsymbol{A})$ and aspartate $(O)$. The numbers in parentheses indicate the number of afferents tested at a given concentration. Vertical bars represent SEM. Inset, Responses of one cell (as depicted in Fig. 6) to given concentrations of glutamate (in millimolar concen tration). In this case, $5 \mathrm{mM}$ glutamate produced depolarization inactivation of the afferent. $B$, Responses of afferents to given concentrations

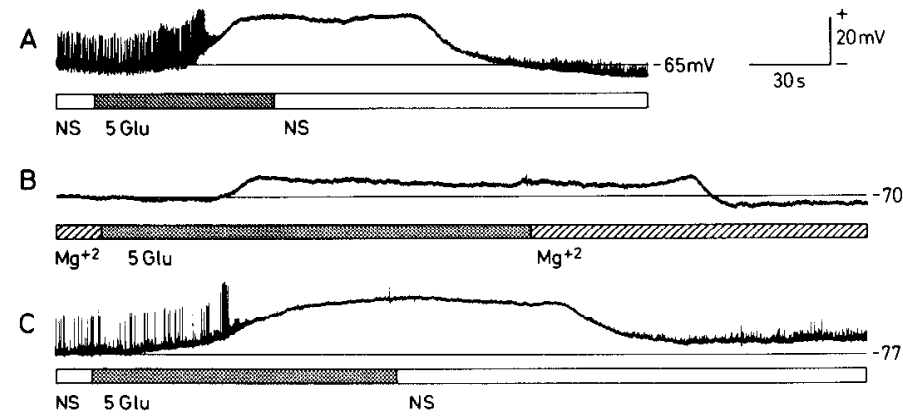

Figure 8. Depolarizing effect of glutamate on an afferent fiber. $A$ to $C$. Intracellular recording from a single afferent. $A$, Bath application of $5 \mathrm{mM}$ glutamate $(5 \mathrm{Glu})$ resulted in a reversible depolarization. $B$, Same cell in $10 \mathrm{mM} \mathrm{Mg}{ }^{2+} / 1 \mathrm{mM} \mathrm{Ca}^{2+}$, when spontaneous synaptic activity was blocked. Glutamate persisted in depolarizing the afferent. $C$, After returning to normal saline $(N S)$, glutamate again evokes a reversible depolarization. Action potentials are truncated due to the low frequency response limitations of the chart recorders. Numbers to the right of each trace indicate DC potential levels as indicated by horizontal lines.

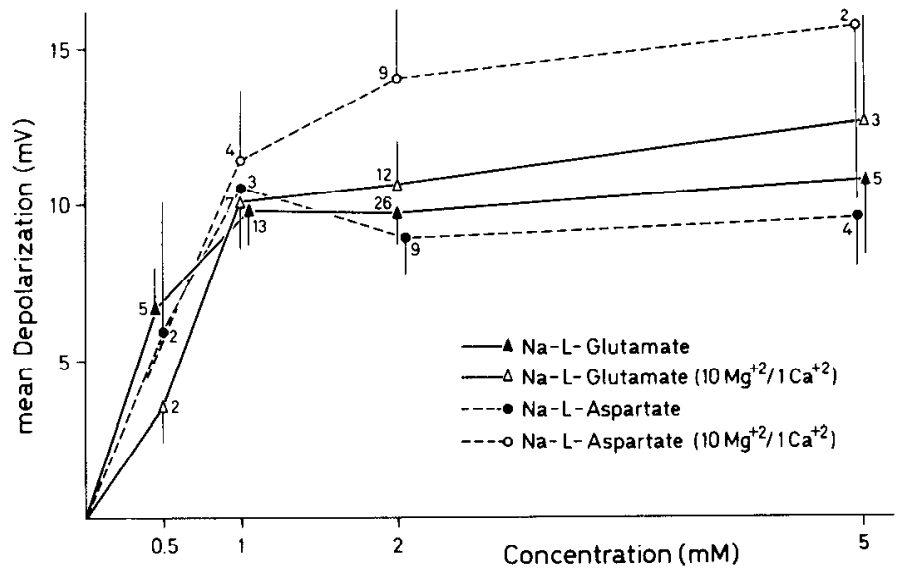

Figure 9. Dose-response curves of the depolarizing actions of glutamate and aspartate in normal saline and in the presence of $10 \mathrm{mM}$ $\mathrm{Mg}^{2+} / 1 \mathrm{mM} \mathrm{Ca}{ }^{2+}$ (when spontaneous synaptic activity was blocked). The numbers in parentheses represent the number of cells for each point. Vertical bars represent SEM.

but appears to be "glutamatergic." Unlike cholinergic agonists, which have varying effects on the afferent activity (Table I), glutamate and its related acidic amino acids produce depolarizations consistently. Such depolarizations are most likely postsynaptic as indicated by the ability of the acidic amino acid (at least glutamate and aspartate) to depolarize the afferent when the presynaptic depolarization-secretion coupling mechanisms are blocked in high $\mathrm{Mg}^{2+} /$ low $\mathrm{Ca}^{2+}$. However, this finding does not rule out the remote possibility that glutamate could act presynaptically through $\mathrm{Ca}^{2+}$-independent mechanisms, could work on non-synaptic regions of the afferent membrane, and/ or could act to release $\mathrm{K}^{+}$from glial or other supporting cells and then indirectly depolarize the afferent. This point is particularly problematic as bath application of a substance is quite a different means of administration than having the same substance released, presumably as quanta, from a nerve termi-

of acidic amino acids. The numbers in parentheses represent the number of afferents tested at a given concentration. Vertical bars represent SEM. Abbreviations are as in Figure 6. $\Delta F$ represents the peak frequency attained during drug application minus the resting firing frequency of the axon prior to drug administration. Hcys, homocysteic acid. 
A
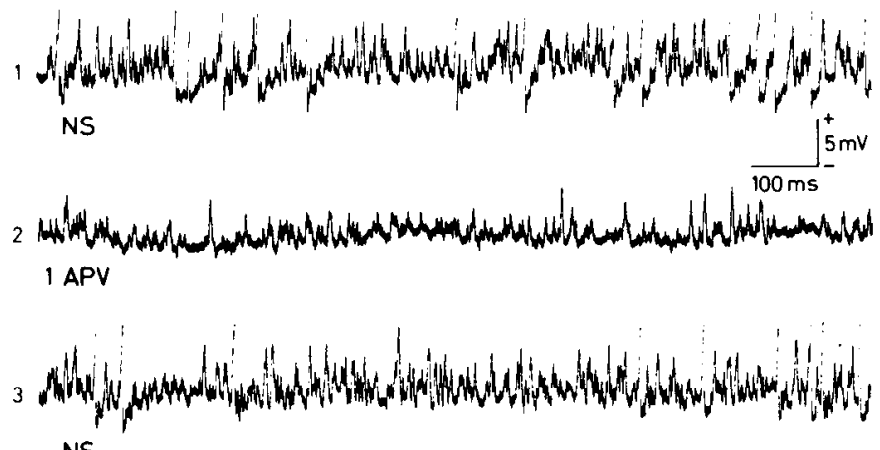

NS

B

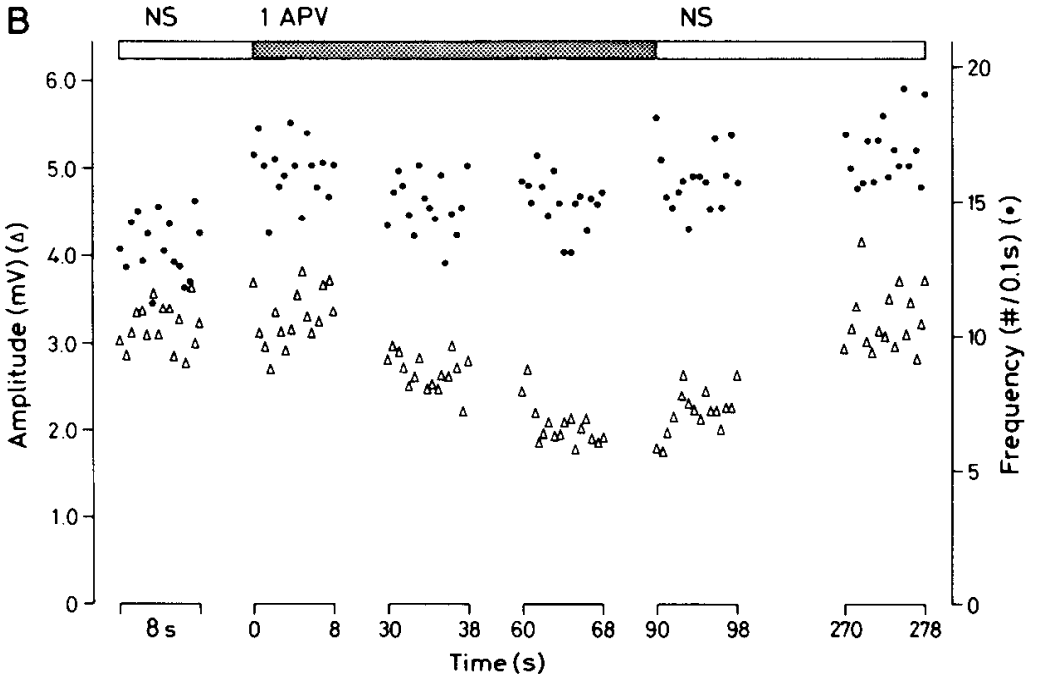

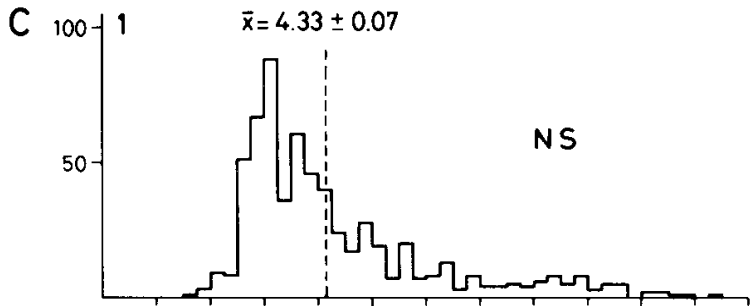
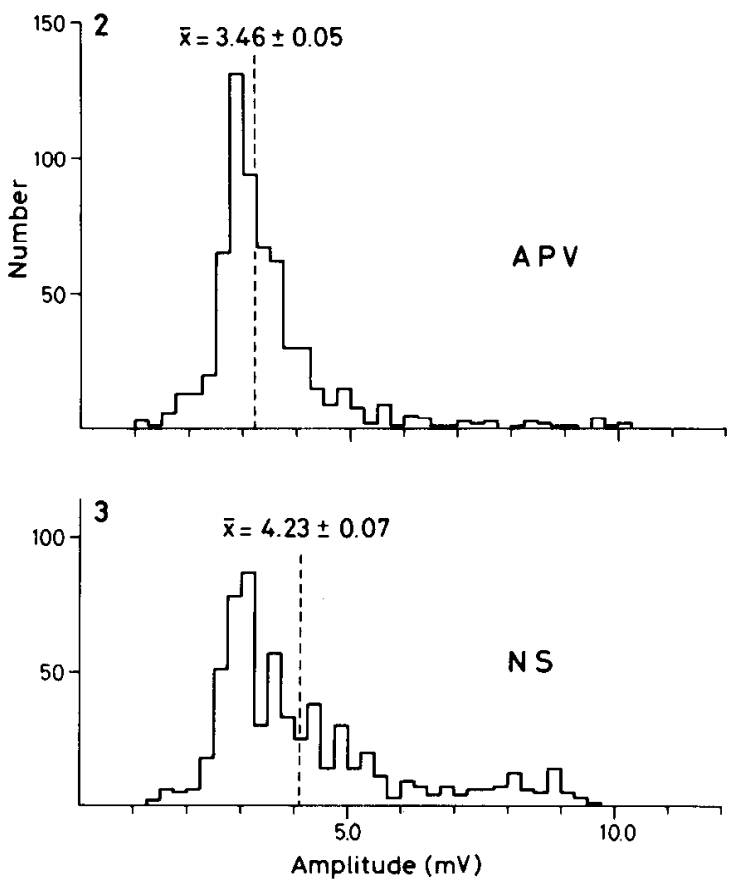

Figure 10. Effect of 2-amino-5-phosphonovaleric acid $(A P V)$ upon the spontaneous synaptic potentials. $A$, Intracellular recordings from an afferent fiber in normal saline $(A 1)$, after the addition of $1 \mathrm{mM} \mathrm{APV}(A 2)$, and after a prolonged wash in normal saline (A3). Action potentials are cut off. $B$, Plots of amplitude $(\triangle)$ and frequency $(\Theta)$ of spontaneous synaptic potentials in the same cell as in $A$, prior to (first $N S$ ), during $(A P V)$, and following (second NS) the addition of $1 \mathrm{mM} \mathrm{APV.C}$, Histograms of spontaneous synaptic potential amplitudes in the same cell as in $A$ and $B$ prior to $(C I)$, during $(C 2)$, and following (C3) the addition of $1 \mathrm{mM} \mathrm{APV}$. Note the shift of distribution to the left in $C 2$ and recovery in $C 3$.

nal. Unlike the neuromuscular junction, where both applied acetylcholine and the synaptic release can desensitize postsynaptic receptors (Thesleff, 1955; Katz and Thesleff, 1957), in the vestibular afferents neither are the synaptic potentials altered during high frequency release (Fig. 2) nor are the depolarizations induced by glutamate and aspartate subject to obvious desensitization or tachyphylaxis (Figs. 13 and 14). A wide range of glutamate antagonists also block synaptic transmission. This blockade is subsynaptic since the amplitudes of the spontaneous synaptic potentials are reduced, while the frequency of their occurrence is not consistently altered. These same antagonists reduce the postsynaptic depolarizations evoked by the acidic amino acids, again implicating glutamate or a related substance as the transmitter at this synapse.

None of our data support the previous claims (Flock and Lam, 1974; Meza et al., 1982; Felix and Ehrenberger, 1982) that GABA is a hair cell transmitter. Although we found that GABA and its potent agonist muscimol could excite the afferents, no effect was seen in intracellular recordings from $\mathrm{Mg}^{2+}$. blocked preparations. Therefore, the effects of GABA appear to be presynaptic. Picrotoxin was also found to be ineffective in reducing the amplitude of the spontaneous synaptic potentials, recorded intracellularly. It could be argued that glutamate may be the transmitter of the type II hair cell (present in the frog), while GABA is the transmitter of the type I hair cell (present with the type II cell in higher vertebrates). However, GABA and the enzyme that synthesizes it are present in the labyrinth of frogs (Flock and Lam, 1974; G. Meza, personal communication) as well as in higher vertebrates (Meza et al., 1982). It could also be argued that otolithic organs have hair cells with GABA as the transmitter, while the canal hair cells utilize the acidic amino acids. However, we have found that GDEE and KENYA are both capable of blocking spontaneous synaptic potentials (i.e., by reducing their amplitude) in otolith afferents (J. -M. Annoni, S. L. Cochran, and W. Precht, unpublished observations). Rossi et al. (1980) have reported a noncholinergic population of afferents that is capable of exciting vestibular afferents, presumably via increasing transmitter release from hair cells. Therefore, the most likely explanation of the actions of GABA is that, rather than performing as the hair cells' transmitter, it acts as a facilitatory transmitter from one of the centrally arising efferents. Further studies are necessary to determine if this is the case.

The hair cell-afferent fiber synapse is "glutamatergic" in the sense referred to by Dale (1933). However, the nature of the actual chemical mediator is not discernible from our studies. This limitation is in part due to the technical limitations encountered when attempting to maintain steady recordings for long periods of time. Unusually, every substance reported to be a "glutamate" antagonist (McLennan et al., 1981; Puil, 
A

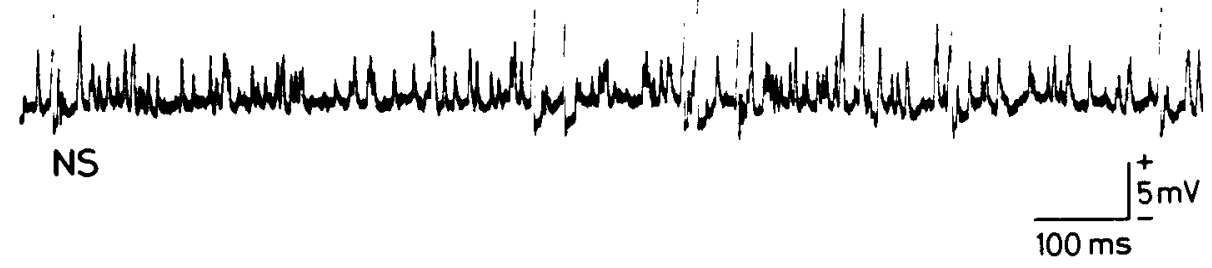

2

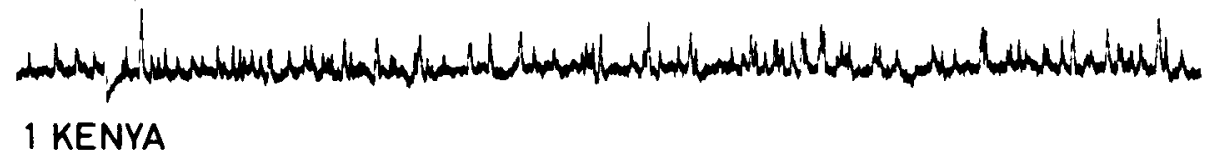

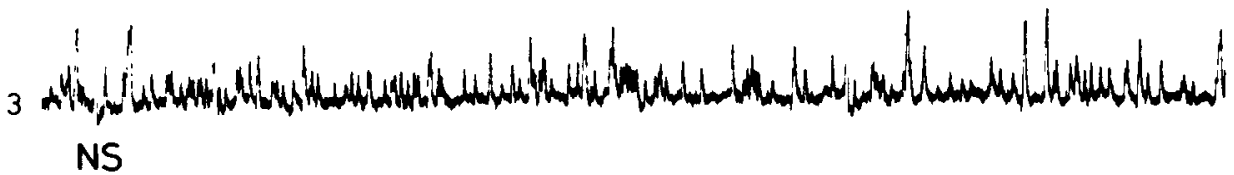

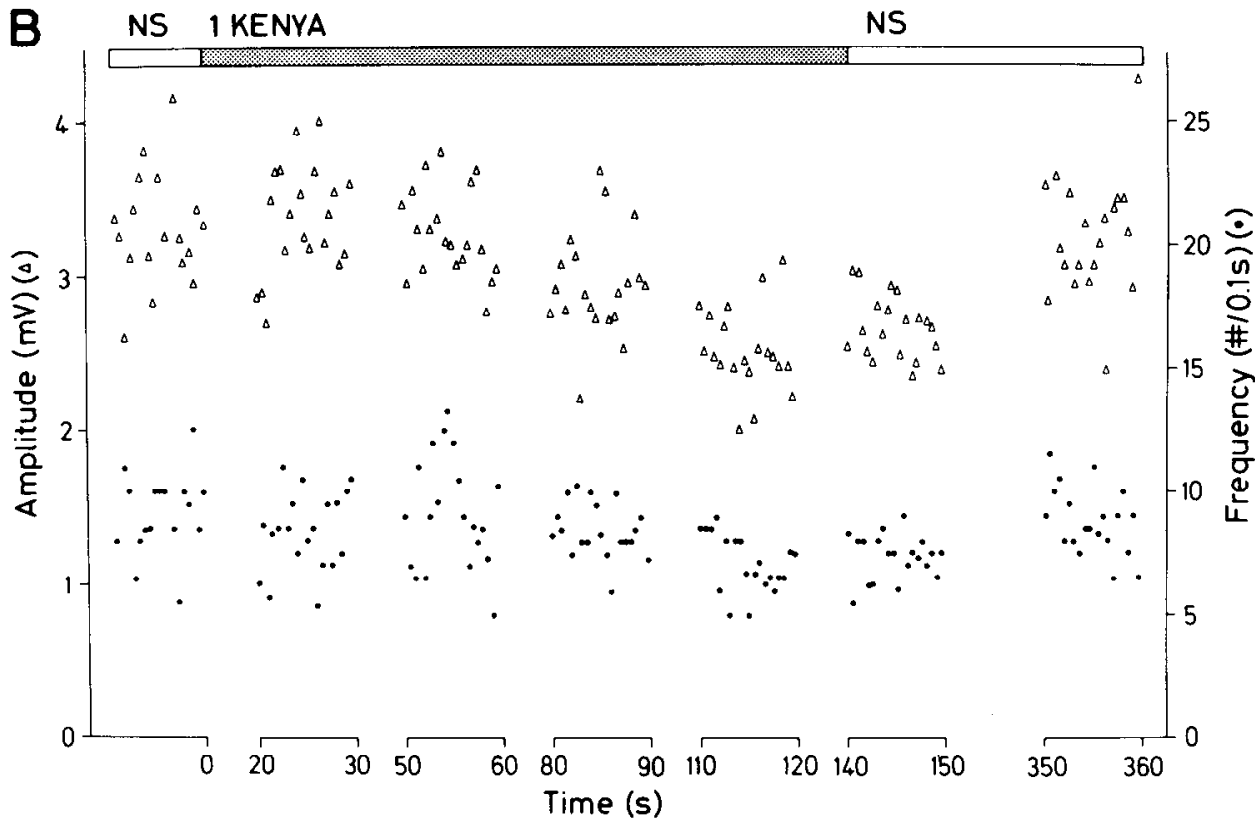

Figure 11. Effect of kynurenic acid (KENYA) upon the spontaneous synaptic potentials as in Figure 10. $A$, Intracellular recordings from an afferent fiber. $B$, Plots of amplitude $(\triangle)$ and frequency

(O) of the spontaneous synaptic potentials from the same cell shown in $A$.

1981; Watkins and Evans, 1981), except for $\mathrm{Mg}^{2+}$ (Ault et al., 1980; Davies and Watkins, 1980), antagonizes the synaptic activity at this synapse. This is not true in other systems, such as the spinal cord (Watkins and Evans, 1981; Davies and Watkins, 1983; Peet et al., 1983), the cerebellum (Cochran, 1983), the olfatory cortex (Hori et al., 1981), or the hippocampus (Collingridge et al., 1983a, b), where certain specificities of antagonist action have been reported. A logical explanation of this generality of antagonist effect is that the synaptic receptor is of the "N-methyl-D-aspartic acid (NMDA) type" and that the concentrations of all of the antagonists used in this study are high enough to affect the "NMDA receptor." However, $\mathrm{Mg}^{2+}$ ions are reported to antagonize the NMDA receptormediated excitation (Ault et al., 1980; Davies and Watkins, 1980 ), and as we see no consistent reduction of either the amplitude of synaptic potentials (Fig. 3) or of the acidic amino acid-induced excitations (Fig. 9) in high $(10 \mathrm{mM})$ concentrations of $\mathrm{Mg}^{2+}$, it seems quite unlikely that there is a postsynaptic effect of $\mathrm{Mg}^{2+}$. Therefore, this receptor is clearly not the "NMDA type" described in the spinal cord. Thus, this synaptic receptor on the vestibular afferent may be rather aspecific in terms of the actions of the antagonists. The synaptic receptor could then represent an "aggregate," heterogeneous receptor composed of many specific types of receptor or a generalized, homogeneous receptor with aspecific sensitivity to the known antagonists (see also the discussion by Puil, 1981).

Similarly, the acidic amino acid agonists are capable of activating the afferent fiber directly, when depolarization-secretion coupling is blocked, and perhaps subsynaptically. Which substance or substances are the endogeneous agonist(s) is not clear. Aspartate-induced depolarizations are more sensitive to antagonism that are those induced by glutamate (Figs. 13,14 and 15). Thus, aspartate would seem to be a more likely candidate as the transmitter. However, the concentration of transmitter that reaches the synaptic receptor is not known, and it is quite possible that a lower concentration of glutamate is released than would be necessary for aspartate. Alternatively, both glutamate and aspartate (and/or something else) could be released from a hair cell.

While our experiments have to a large extent fulfilled the 
(A)
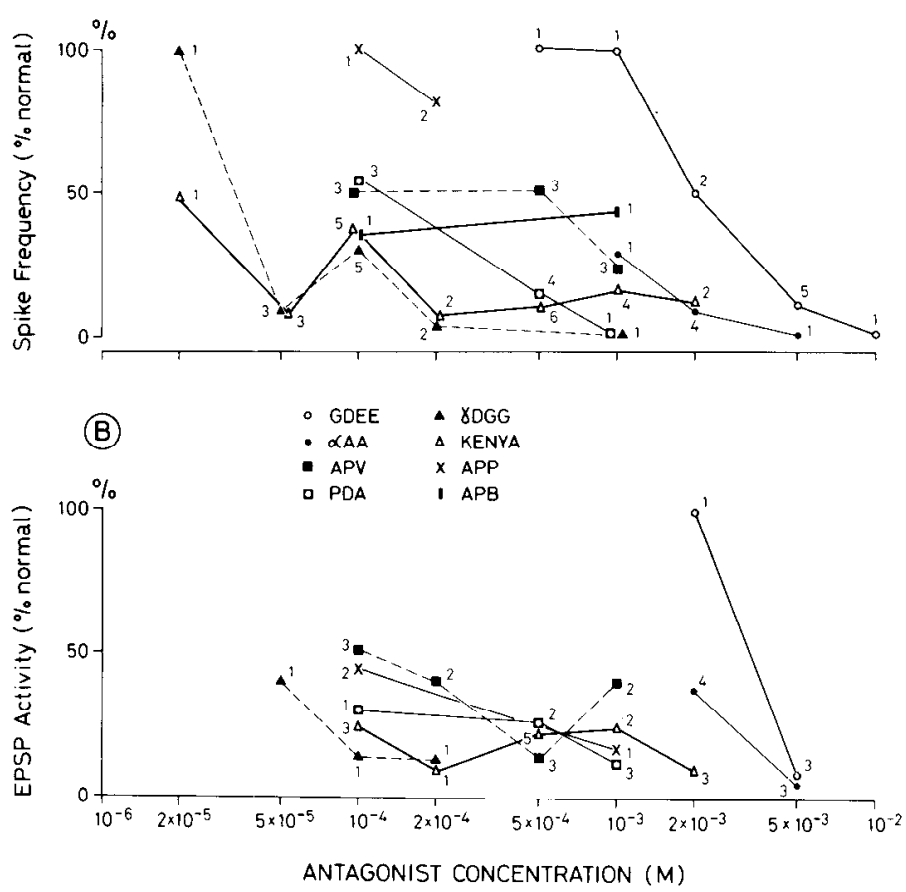

Figure 12. Effect of acidic amino acid antagonists upon spontaneous afferent activity. $A$, Effect upon spike frequency, recorded intra-cellularly. In $A$ and $B$, frequency was determined by an amplitude threshold discriminator. Numbers represent the numbers of cells tested at each concentration for each substance. GDEE, glutamic acid diethyl ester; $\alpha A A, \alpha$-aminoadipic acid; $A P V, 2$-amino-5-phosphonovaleric acid; $P D A$, cis-2,3-piperidine dicarboxylic acid; $\gamma D G G, \gamma$-D-glutamylglycine; $K E N Y A$, kynurenic acid; $A P P, 2$-amino-3-phosphonopropionic acid; $A P B, 2$-amino-4-phosphonobutyric acid
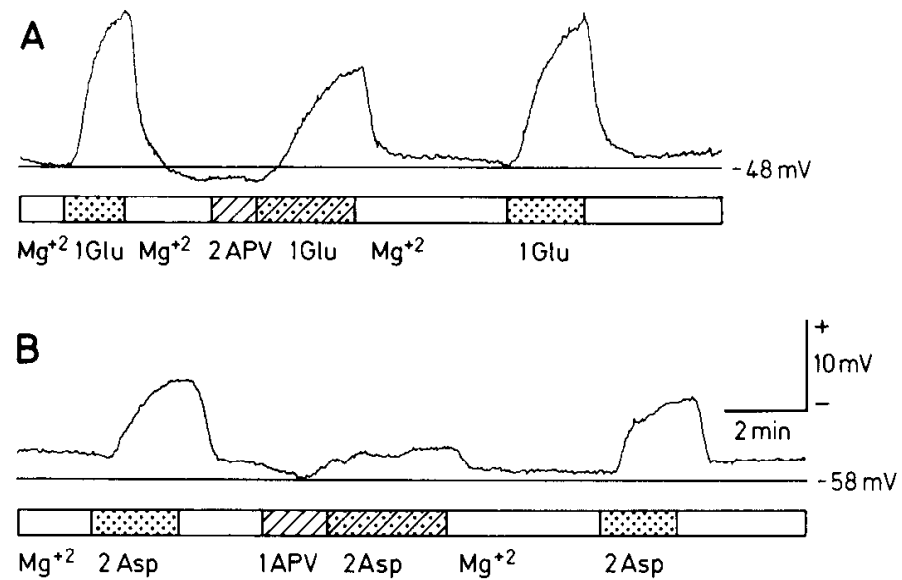

Figure 13. Effect of APV on postsynaptic depolarizations of glutamate $(A)$ and aspartate $(B)$ on two different cells. In both $A$ and $B$ the recordings were taken in $10 \mathrm{mM} \mathrm{Mg}^{2+} / 1 \mathrm{mM} \mathrm{Ca}^{2+}$, when spontaneous synaptic activity was blocked. Note the higher concentration of APV needed to reduce the effect of glutamate. Numbers beside substances indicate millimolar concentrations. The horizontal lines are as in Figure 8.

criterion of "identity of action" (see Eccles, 1964) at this synapse, further studies are needed to resolve the above uncertainties. It is quite possible that glutamate and aspartate have different reversal potentials. If these could be compared with the reversal potential of the synaptic potentials, then perhaps a distinction could be made as to which is the real transmitter.

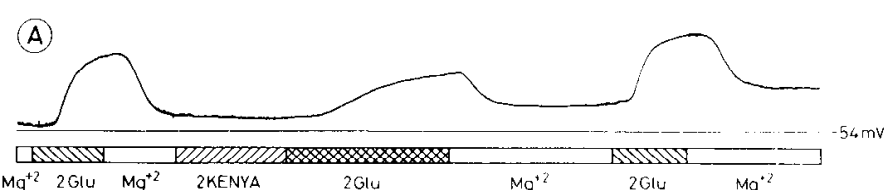

(B)
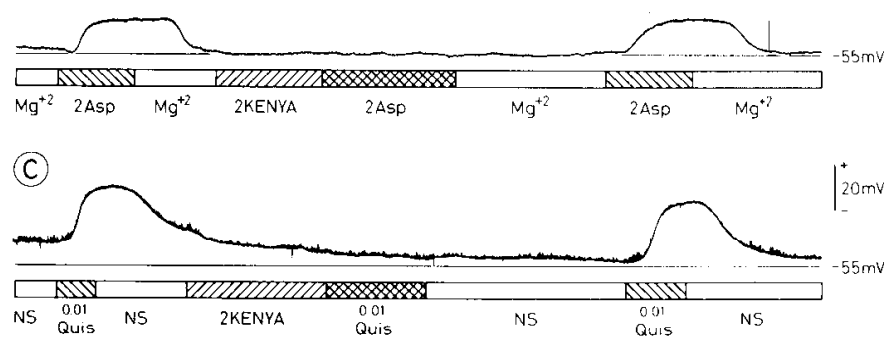

Figure 14. Effect of KENYA on depolarizations due to glutamate $(A)$, aspartate $(B)$, and quisqualic acid $(C)$ in three different afferents. $A$ and $B$ were recorded in the presence of $10 \mathrm{mM} \mathrm{Mg}{ }^{2+} / 1 \mathrm{mM} \mathrm{Ca}^{2+}$, when spontaneous synaptic activity was blocked. Note the persistence of the glutamate effect when both aspartate and quisqualic acid were blocked. Numbers besides the substances indicate millimolar concentrations. The horizontal lines are as in Figures 8 and 13

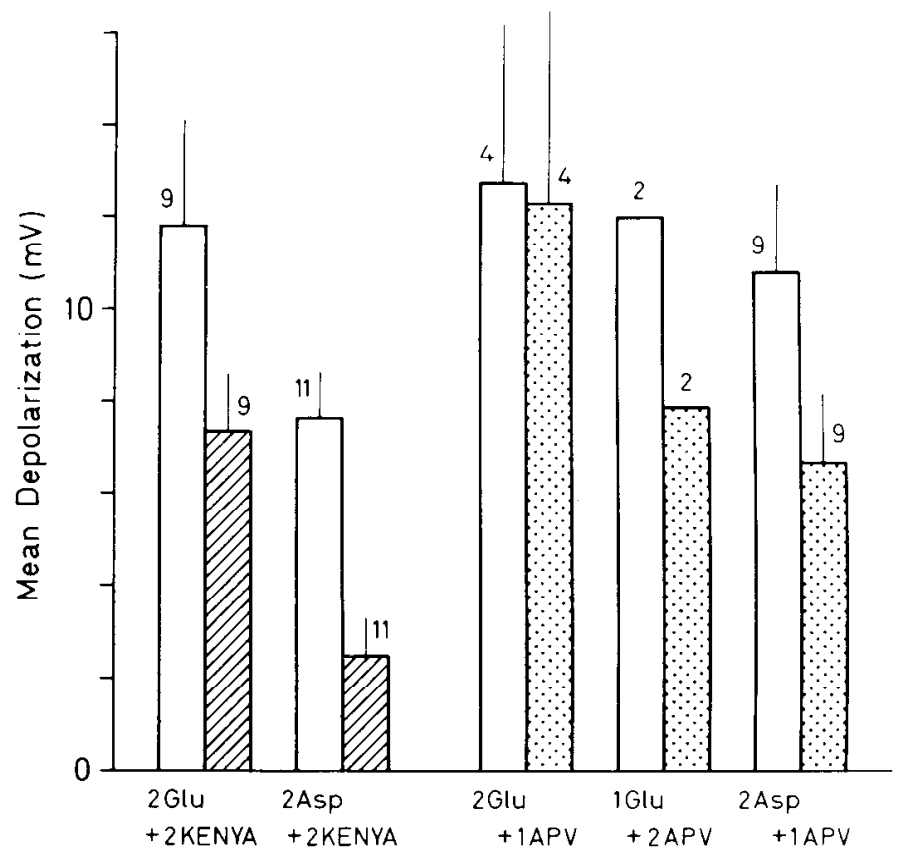

Figure 15. Summary of the effects of KENYA and APV on the postsynaptic depolarizations of glutamate and aspartate. ()pen columns indicate the depolarizing effects of substances in the presence of 10 $\mathrm{mM} \mathrm{Mg}^{2+} / 1 \mathrm{mM} \mathrm{Ca}^{2+}$. Shaded columns indicate persistent depolarizations in the presence of the indicated antagonists. Numbers beside the substances indicate millimolar concentrations. Numbers on top of columns indicate the number of cells tested for each. Vertical bars represent the SEM.

However, the small size of the afferents hinders such an analysis, and recent findings in the hippocampus suggest that even this criterion may not be useful in distinguishing agonists (Crunelli et al., 1984). The development of more specific acidic amino acid antagonists might lead to a clearly selective antag. onism of just the subsynaptic receptor and of just the action of an applied substance. However, the apparent generalized nature of this receptor would seem to bely that approach. This criterion of "identity of action" is one of the strongest in identifying a 


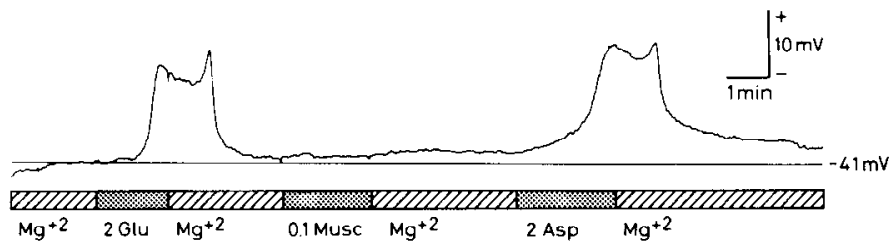

Figure 16. Effects of glutamate, muscimol (Musc), and aspartate upon the membrane potential of an afferent fiber in the presence of 10 $\mathrm{mM} \mathrm{Mg}^{2+} / 1 \mathrm{mM} \mathrm{Ca}{ }^{2+}$, when the spontaneous synaptic activity was blocked. Numbers beside the substances indicate millimolar concentrations. The horizontal line is as in Figure 8.

synaptic transmitter. However, particularly with respect to "glutamatergic" synapses, the determination of the particular substance(s) involved in synaptic transmission must await the fulfillment of further criteria.

\section{References}

Annoni, J. -M., S. L. Cochran, and W. Precht (1983a) Glutamate or a related substance may be the transmitter at the hair cell-primary afferent synapse in the vestibular labyrinth of the frog (Rana temporaria). Experientia 39: 628 .

Annoni, J. -M., S. L. Cochran, and W. Precht (1983b) Synaptic- and amino acid-induced excitation and antagonism at the vestibular hair cell-primary afferent synapse of the frog. Neurosci. Lett. (Suppl.) 14: 9.

Ault, B., R. H. Evans, A. A. Francis, D. J. Oakes, and J.C. Watkins (1980) Selective depression of excitatory amino acid induced depolarizations by magnesium ions in isolated spinal cord preparations. J. Physiol. (Lond.) 307: 413-428.

Bernard, C., S. L. Cochran, and W. Precht (1984) Cholinergic actions upon vestibular afferent activity in the frog. J. Physiol. (Paris), in press.

Bobbin, R. P. (1979) Glutamate and aspartate mimic the afferent transmitter in the cochlea. Exp. Brain Res. 34: 389-393.

Brown, K. T., and D. G. Flaming (1974) Beveling of fine micropipette electrodes by a rapid precision method. Science 185: 693-695.

Cochran, S. L. (1983) Pharmacological antagonism of climbing fiber-, parallel fiber-, and acidic amino acid-induced excitation of frog cerebellar Purkinje cells. Soc. Neurosci. Abstr. 9: 1142.

Collingridge, G. L., S. J. Kehl, and H. McLennan (1983a) The antagonism of amino acid-induced excitations of rat hippocampal CA1 neurones in vitro. J. Physiol. (Lond.) 334: 19-31.

Collingridge, G. L., S. L. Kehl, and H. McLennan (1983b) Excitatory amino acids in synaptic transmission in the Schaffer collateralcommissural pathway of the rat hippocampus. J. Physiol. (Lond.) 334: $33-46$

Comis, S. D., and G. Leng (1979) Action of putative neurotransmitters in the guinea pig cochlea. Exp. Brain Res. 36: 119-128.

Crunelli, V., S. Forda, J. S. Kelly, and J. C. M. Wise (1984) The reversal potentials for depolarization induced by excitatory amino acids and the perforant-path-evoked EPSP. J. Physiol. (Lond.) 346: $41 \mathrm{P}$.

Dale, H. H. (1933) Nomenclature of fibres in the autonomic system and their effects. J. Physiol. (Lond.) 80: 10-11.

Davies, J., and J. C. Watkins (1980) Effect of magnesium ions in the responses of spinal neurons to excitatory amino acids and acetylcholine. Brain Res. 130: 364-368.

Davies, J., and J. C. Watkins (1983) Role of excitatory amino acid receptors in the mono- and polysynaptic excitation in cat spinal cord. Exp. Brain Res. 49: 280-290.

Del Castillo, J., and B. Katz (1954) Changes in endplate activity produced by presynaptic polarization. J. Physiol. (Lond.) 124: 586604
Eccles, J. C. (1964) The Physiology of Synapses, Springer-Verlag, New York.

Fatt, P., and B. Katz (1952) Spontaneous subthreshold activity at motor nerve endings. J. Physiol. (Lond.) 117: 109-128.

Felix, D., and D. Ehrenberger (1982) The action of putative neurotransmitter substances in the cat labyrinth. Acta Otolaryngol. 93: 101-105.

Flock, A., and D. M. K. Lam (1974) Neurotransmitter synthesis in inner ear and lateral line sense organs. Nature 249: 142-144.

Furukawa, T., Y. Ishii, and S. Matsura (1972) Synaptic delay and time course of post-synaptic potentials at the junction between hair cells and eighth nerve fibers in the goldfish. Jpn. J. Physiol. 22: 617-635.

Hackett, J. T. (1976) Calcium dependency of excitatory chemical synaptic transmission in the frog cerebellum in vitro. Brain Res. 114: $35-46$.

IIillman, D.E. (1976) Morphology of peripheral and central vestibular systems. In Frog Neurobiology, R. Llinas and W. Precht, eds., pp. 452-480, Springer-Verlag, Berlin.

Hori, N., C. R. Auker, D. L. Braitman, and D. O. Carpenter (1981) Lateral olfactory tract transmitter: Glutamate, aspartate, or neither? Cell. Mol. Neurobiol. 1: 115-120.

Hudspeth, A. J., and R. Jacobs (1979) Stereocilia mediate transduction in vertebrate hair cells. Proc. Natl. Acad. Sci. U. S. A. 76: 1506-1509.

Katz, B., and S. Thesleff (1957) A study of the "desensitization" produced by acetylcholine at the motor endplate. J. Physiol. (Lond.) 138: $63-80$.

Klinke, R., and W. Oertel (1977) Amino acids-putative afferent transmitter in the cochlea? Exp. Brain Res. 30: 145-148.

McLennan, H., T. P. Hicks, and J. G. Hall (1981) Receptors for the excitatory amino acids. In Amino Acid Neurotransmitters, F. V. DeFeudis and P. Mandel, eds., pp. 213-221, Raven Press, New York

Meza, G., A. Carabez, and M. Ruiz (1982) GABA synthesis in isolated vestibularly tissue of chick inner ear. Brain Res. 241: 157-161.

Osborne, M. P., and R. A. Thornhill (1972) The effect of monoamine depleting drugs upon the synaptic bars in the inner ear of the bullfrog (Rana catesbeiana). Z. Zellforsch. 127: 347-355.

Peet, M. J., and J. D. Leah, and D. R. Curtis (1983) Antagonists of synaptic and amino acid excitation of neurones in the cat spinal cord. Brain Res. 266: 83-95.

Perkins, M. N., and T. W. Stone (1982) An iontophoresis investigation of the actions of convulsant kynurenines and the interaction with the endogeneous excitant quinolinic acid. Brain Res. 247: 184-187.

Puil, E. (1981) $S$-Glutamate: Its interactions with spinal neurons. Brain Res. Rev. 3: 229-322.

Quastel, D. M. J., J. T. Hackett, and J. D. Cooke (1971) Calcium: Is it required for transmitter secretion? Science 172: 1034-1036.

Rossi, M. L., Valli, and C. Casella (1977) Post-synaptic potentials recorded from afferent nerve fibres of the posterior semicircular canal in the frog. Brain Res. 135: 67-75.

Rossi, M. L., I. Prigioni, P. Valli, and C. Casella (1980) Activation of the efferent system in the isolated frog labyrinth: Effects on the afferent EPSPs and spike discharge recorded from single fibres of the posterior nerve. Brain Res. 185: 125-137.

Russell, I. J. (1971) The pharmacology of efferent synapses in the lateral-line system of Xenopus laevis. J. Exp. Biol. 54: 643-658.

Sonnhof, U., R. Forderer, W. Schneider, and H. Kettenman (1982) Cell puncturing with a step motor driven manipulator with simultaneous measurement of displacement. Pflügers Arch. 392: 295300.

Steinbach, A. B., and M.V. L. Bennett (1971) Effects of divalent cations and drugs on synaptic transmission in phasic electroreceptors in a mormyrid fish. J. Gen. Physiol. 58: 580-598.

Teeter, J. H., and M. V. L. Bennett (1981) Synaptic transmission in the ampullary electroreceptor of the transparent cat-fish, Kryptoperus. J. Comp. Physiol. 142: 371-377.

Thesleff, S. (1955) The mode of neuromuscular block caused by acetylcholine, nicotine, decamethonium and succinylcholine. Acta Physiol. Scand. 34: 218-231.

Watkins, J. C., and R. H. Evans (1981) Excitatory amino acid transmitters. Annu. Rev. Pharmacol. Toxicol. 21: 165-204. 